\title{
The effects of vitamin D and omega-3 fatty acids co-supplementation on biomarkers of inflammation, oxidative stress and pregnancy outcomes in patients with gestational diabetes
}

Maryamalsadat Razavi ${ }^{1}$, Mehri Jamilian ${ }^{2 *}$, Mansooreh Samimi ${ }^{3}$, Faraneh Afshar Ebrahimi ${ }^{3}$, Mohsen Taghizadeh ${ }^{4}$, Reza Bekhradi ${ }^{5}$, Elahe Seyed Hosseini ${ }^{6}$, Hamed Haddad Kashani ${ }^{6}$, Maryam Karamalii and Zatollah Asemi ${ }^{4^{*}}$

\begin{abstract}
Background: This study was carried out to determine the effects of vitamin D and omega-3 fatty acids cosupplementation on biomarkers of inflammation, oxidative stress and pregnancy outcomes in gestational diabetes (GDM) patients.

Methods: This randomized, double-blind, placebo-controlled trial was conducted among 120 GDM women. Participants were randomly divided into four groups to receive: 1) $1000 \mathrm{mg}$ omega-3 fatty acids containing $180 \mathrm{mg}$ eicosapentaenoic acid (EPA) and $120 \mathrm{mg}$ docosahexaenoic acid (DHA) twice a day + vitamin D placebo $(n=30) ; 2) 50,000 \mathrm{IU}$ vitamin D every 2 weeks + omega-3 fatty acids placebo $(n=30) ; 3) 50,000$ IU vitamin D every 2 weeks + 1000 mg omega-3 fatty acids twice a day $(n=30)$ and 4) vitamin D placebo + omega-3 fatty acids placebo $(n=30)$ for 6 weeks.

Results: Subjects who received vitamin D plus omega-3 fatty acids supplements compared with vitamin $D$, omega-3 fatty acids and placebo had significantly decreased high-sensitivity C-reactive protein $(-2.0 \pm 3.3$ vs. $-0.8 \pm 4.4,-1.3 \pm 2.4$ and $+0.9 \pm 2.7 \mathrm{mg} / \mathrm{L}$, respectively, $P=0.008)$, malondialdehyde ( $-0.5 \pm 0.5 \mathrm{vs} .-0.2 \pm 0.5,-0.3 \pm 0.9$ and $+0.5 \pm 1.4 \mu \mathrm{mol} / \mathrm{L}$, respectively, $P<0.001)$, and increased total antioxidant capacity ( $+92.1 \pm 70.1$ vs. $+55.1 \pm 123.6,+88.4 \pm 95.2$ and $+1.0 \pm 90$. $8 \mathrm{mmol} / \mathrm{L}$, respectively, $P=0.001)$ and glutathione (+95.7 $\pm 86.7 \mathrm{vs} .+23.0 \pm 62.3,+30.0 \pm 66.5$ and $-7.8 \pm 126.5 \mu \mathrm{mol} / \mathrm{L}$, respectively, $P=0.001$ ). In addition, vitamin $D$ and omega-3 fatty acids co-supplementation, compared with vitamin $D$, omega-3 fatty acids and placebo, resulted in lower incidences of newborns' hyperbilirubinemiain $(P=0.037)$ and newborns' hospitalization $(P=0.037)$.
\end{abstract}

Conclusion: Overall, vitamin D and omega-3 fatty acids co-supplementation for 6 weeks among GDM women had beneficial effects on some biomarkers of inflammation, oxidative stress and pregnancy outcomes.

Keywords: Vitamin D, Omega-3 fatty acids, Supplementation, Gestational diabetes, Pregnancy outcomes

\footnotetext{
*Correspondence: jamilian.mehri@gmail.com; asemi_r@yahoo.com

${ }^{2}$ Endocrinology and Metabolism Research Center, Department of Gynecology and Obstetrics, School of Medicine, Arak University of Medical Sciences, Arak, Iran

${ }^{4}$ Research Center for Biochemistry and Nutrition in Metabolic Diseases, Kashan University of Medical Sciences, PO Box 8715988141, Kashan, Iran Full list of author information is available at the end of the article
} 


\section{Background}

Gestational diabetes mellitus (GDM) is impaired glucose tolerance and insulin resistance with first onset during pregnancy [1]. It affect approximately $5 \%$ of all pregnancies worldwide [2]. The its prevalence in US [3] and Iran [4] was reported 5.8 and $4.7 \%$, respectively. GDM is associated with serious maternal and fetal complications including pre-eclampsia, fetal macrosomia, shoulder dystocia, neonatal hypoglycemia and maternal complications [5]. In addition, a 7-fold increased risk for developing type 2 diabetes mellitus (T2DM) was reported in GDM women [6]. Increased inflammatory factors contribute to pregnancy-induced insulin resistance and the development of glucose intolerance [7]. Hyperglycemia in GDM increases oxidative stress through several molecular mechanisms including the activation of protein kinase $\mathrm{C}$ and increased reactive oxygen species production in mitochondria [8].

Previous studies have reported that vitamin D [9] and omega-3 fatty acids levels [10] were low in GDM patients than those healthy pregnant women. Earlier, the beneficial effects of single supplementation with vitamin D or omega-3 fatty acids on biomarkers of inflammation, oxidative stress and pregnancy outcomes in GDM women were reported $[11,12]$. We are aware of no study that examined the effect of vitamin D or omega-3 fatty acids co-supplementation on inflammatory factors, biomarkers of oxidative stress and pregnancy outcomes in GDM. Nowadays, there is a growing interest to use vitamin $\mathrm{D}$ and omega-3 fatty acids during pregnancy especially in GDM women. In a study by Mojibian et al. [13], it was observed that supplementation with 50,000 IU vitamin $\mathrm{D}$ every 2 weeks to women with gestational age 12-16 weeks until delivery decreased the incidence of GDM, but did not affect the incidence of pre-eclampsia, gestational hypertension, preterm labor, and low birth weight. Furthermore, in a meta-analysis study, omega3 fatty acids supplementation during pregnancy was associated with the reduced risk of preterm delivery and improved size of the newborn [14]. However, docosahexaenoic acid (DHA) supplementation of $800 \mathrm{mg} /$ day in the second half of pregnancy could not reduce the risk of GDM or pre-eclampsia [15].

There are speculations that vitamin $\mathrm{D}$ and omega-3 fatty acids may improve biomarkers of inflammation and oxidative stress, and pregnancy outcomes due to their effects on maternal metabolic profiles [16], increased metabolism of bile acids [17] and inhibiting the activation of nuclear factor- $\mathrm{kB}(\mathrm{NF}-\mathrm{kB})$ [18]. This study was, therefore, carried out to determine the effects of vitamin D and omega-3 fatty acids cosupplementation on biomarkers of inflammation (primary outcomes), oxidative stress and pregnancy outcomes (secondary outcomes) in GDM women.

\section{Methods}

\section{Trial design and participants}

The present study, registered in the Iranian website for registration of clinical trials (http://www.irct.ir: IRCT20 1701305623N106), was a 6-week randomized doubleblind placebo controlled clinical trial that was carried out among 120 GDM women at 24-28 weeks' gestation, aged 18-40 years without prior diabetes diagnosed based on the American Diabetes Association guidelines [19] from September 2016 to March 2017. This study was approved by the research ethics committee of Ardabil University of Medical Sciences (AUMS) and written informed consent was taken from all patients. Exclusion criteria were taking omega-3 fatty acids supplements, insulin therapy, placenta abruption, pre-eclampsia, eclampsia, hypo and hyperthyroidism, and smokers.

\section{Study design}

At first, participants were randomly assigned into four groups to take either $1000 \mathrm{mg}$ omega-3 fatty acids containing $180 \mathrm{mg}$ eicosapentaenoic acid (EPA) and $120 \mathrm{mg}$ DHA twice a day + vitamin D placebo $(n=30)$ or 50,000 IU vitamin D every 2 weeks + omega- 3 fatty acids placebo $(n=30)$ or 50,000 IU vitamin D every 2 weeks + $1000 \mathrm{mg}$ omega-3 fatty acids twice a day $(n=30)$ or vitamin $\mathrm{D}$ and omega-3 fatty acids placebos $(n=30)$ for 6 weeks. Although, the duration of intervention was 6 weeks, all participants were followed up until the delivery. The placebo capsule contained $500 \mathrm{mg}$ of liquid paraffin. Due to lack of evidence about the appropriate dosage of vitamin D and omega- 3 fatty acids for patients with GDM, we used the above-mentioned dose of vitamin D based on a previous study in GDM women [20] and dose of omega- 3 fatty acids based on a previous study in patients with end-stage renal disease [21]. The appearance of the placebo capsule was indistinguishable in color, shape, size, and packaging, smell and taste from vitamin D and omega-3 fatty acids capsules. Vitamin D and omega-3 fatty acids capsules were produced by Zahravi Pharmaceutical Company, Tabriz, Iran, that approved by Food and Drug Administration. Compliance with the consumption of supplements and placebos was assessed by examining the tablet containers as well as by the measurement of serum 25-hydroxyvitamin D concentrations with the enzyme-linked immunosorbent assay (ELISA) method. To increase compliance, all participants received short messages on their cell phones every day to remind them about taking the capsules. Randomization assignment was conducted using computergenerated random numbers. Randomization and allocation were concealed from the researchers and participants until the final analyses were completed. Another person, who was not involved in the trial and not aware of random sequences, assigned the subjects to the numbered bottles of capsules. 
Subjects were requested not to change their routine physical activity or usual dietary intakes throughout the study and not to consume any supplements other than the one provided to them by the investigators as well as not to take any medications that might affect findings during the 6-wk intervention. Dietary macro- and micro-nutrients intakes were determined using the 3-day food records at weeks $0,3,5$ and 6 of the intervention. Modified Nutritionist-4 software program (First Databank, San Bruno, CA) was used to determine macroand micro-nutrients intakes. Physical activity was described as metabolic equivalents (METs) in hours per day [22].

\section{Assessment of anthropometric measurements}

Weight and height (Seca, Hamburg, Germany) were determined at baseline and after the treatment in a fasting status without shoes and a minimal clothing state by trained staff. BMI was calculated using the height and weight measurements (weight in $\mathrm{kg} /$ [height in meters] $^{2}$ ).

\section{Outcomes}

In the current study, the primary outcomes measurements were inflammatory factors. The secondary outcomes measurements were biomarkers of oxidative stress and pregnancy outcomes.

The measured outcomes of GDM women were biomarkers of inflammation and oxidative, cesarean section, preterm delivery, pre-eclampsia, polyhydramnios and gestational age. The measured outcomes of newborns were macrosomia, newborns' weight, length and head circumference, apgar score, and newborns' hyperbilirubinemia, hospitalization and hypoglycemia.

\section{Assessment of biochemical variables}

Five milliliter fasting blood samples were obtained from each patient at the AUMS reference laboratory, Ardabil, Iran, at baseline and the end of the study. Blood samples was collected in 2 separate tubes: 1) one without EDTA to separate the serum, in order to evaluate serum 25hydroxyvitamin D and high sensitivity C-reactive protein (hsCRP) concentrations and 2) another one containing EDTA to examine plasma nitric oxide (NO), total antioxidant capacity (TAC), total glutathione (GSH) and malondialdehyde (MDA). Blood samples were immediately centrifuged (Hettich D78532, Tuttlingen, Germany) at $3500 \mathrm{rpm}$ for $10 \mathrm{~min}$ to separate the serum. Serum 25-hydroxyvitamin D concentrations were assessed by an ELISA kit (IDS, Boldon, UK) with interand intra-assay coefficient variances $(\mathrm{CVs})$ of 4.4 to $6.6 \%$, respectively. Serum hs-CRP levels were quantified using an ELISA kit (LDN, Nordhorn, Germany) with intra- and interassay CVs of 3.4 and 5.1\%, respectively. The plasma NO levels by Griess method [23], TAC concentrations using the ferric reducing antioxidant power method developed by Benzie and Strain [24], GSH by the method of Beutler et al. [25] and MDA levels by the thiobarbituric acid reactive substance spectrophotometric test [26] were determined. CVs for plasma NO, TAC, GSH and MDA were lower than 5\%.

Newborns' hyperbilirubinemia was considered when the total serum bilirubin levels were at or above $15 \mathrm{mg} /$ $\mathrm{dL}(257 \mathrm{~mol} / \mathrm{L})$ in infants 25 to $48 \mathrm{~h}$ old, $18 \mathrm{mg} / \mathrm{dL}$ (308 mol/L) in infants 49 to $72 \mathrm{~h}$ old, and $20 \mathrm{mg} / \mathrm{dL}$ $(342 \mathrm{~mol} / \mathrm{L})$ in infants older than $72 \mathrm{~h}$ [27].

\section{Clinical assessment}

Polyhydramnios was diagnosed using the sonographic estimation method at post-intervention. On the basis of this measurement, polyhydramnios was defined as an amniotic fluid index (AFI) in excess of $25 \mathrm{~cm}$ [16]. Preterm delivery was defined as delivery occurred at $<37$ weeks of pregnancy and newborn's macrosomia was defined as birth weight of $>4000 \mathrm{~g}$.

\section{Statistical methods}

To calculate the sample size, we used the standard formula suggested for clinical trials by considering type one error $(\alpha)$ of 0.05 and type two error $(\beta)$ of 0.20 (power $=$ $80 \%)$. Based on a previous study [12], we used $1570.5 \mathrm{ng} / \mathrm{mL}$ as SD and $1250.0 \mathrm{ng} / \mathrm{mL}$ as the difference in mean (d) of hs-CRP concentrations as primary variable. Based on this, we needed 25 patients in each group. Considering a dropouts of 5 patients per group, we calculated to have 30 patients per group.

The Kolmogrov-Smirnov test was used to establish the normal distribution of variables. One-way analysis of variance (ANOVA) was used to detect differences in general characteristics and dietary intakes between the four groups. The changes across three groups were compared using Bonferoni post hoc pair-wise comparisons. The Pearson Chi-square test was used to compare categorical variables. To determine the effects of vitamin D plus omega-3 fatty acids supplementation on biomarkers of inflammation and oxidative stress, we used ANOVA. To assess if the magnitude of the change depended on the baseline values, we adjusted all analyses for the baseline values, age and baseline BMI to avoid the potential bias that might have resulted with ANCOVA test. Pvalues $<0.05$ were considered statistically significant. All statistical analyses were done using the Statistical Package for Social Science version 17 (SPSS Inc., Chicago, Illinois, USA).

\section{Results}

Initially, 130 subjects were screened; of whom 10 subjects were excluded due to not living in Ardabil $(n=5)$ and not meeting inclusion criteria. In the current study, 120 GDM women [vitamin D $(n=30)$, omega-3 fatty acids $(n=30)$, vitamin $\mathrm{D}$ plus omega- 3 fatty acids $(n=$ $30)$ and placebo $(n=30)$ ] completed the trial (Fig. 1). On average, the rate of compliance in the present study was high, such that higher than $90 \%$ of capsules were taken throughout the study in both groups. No side effects 


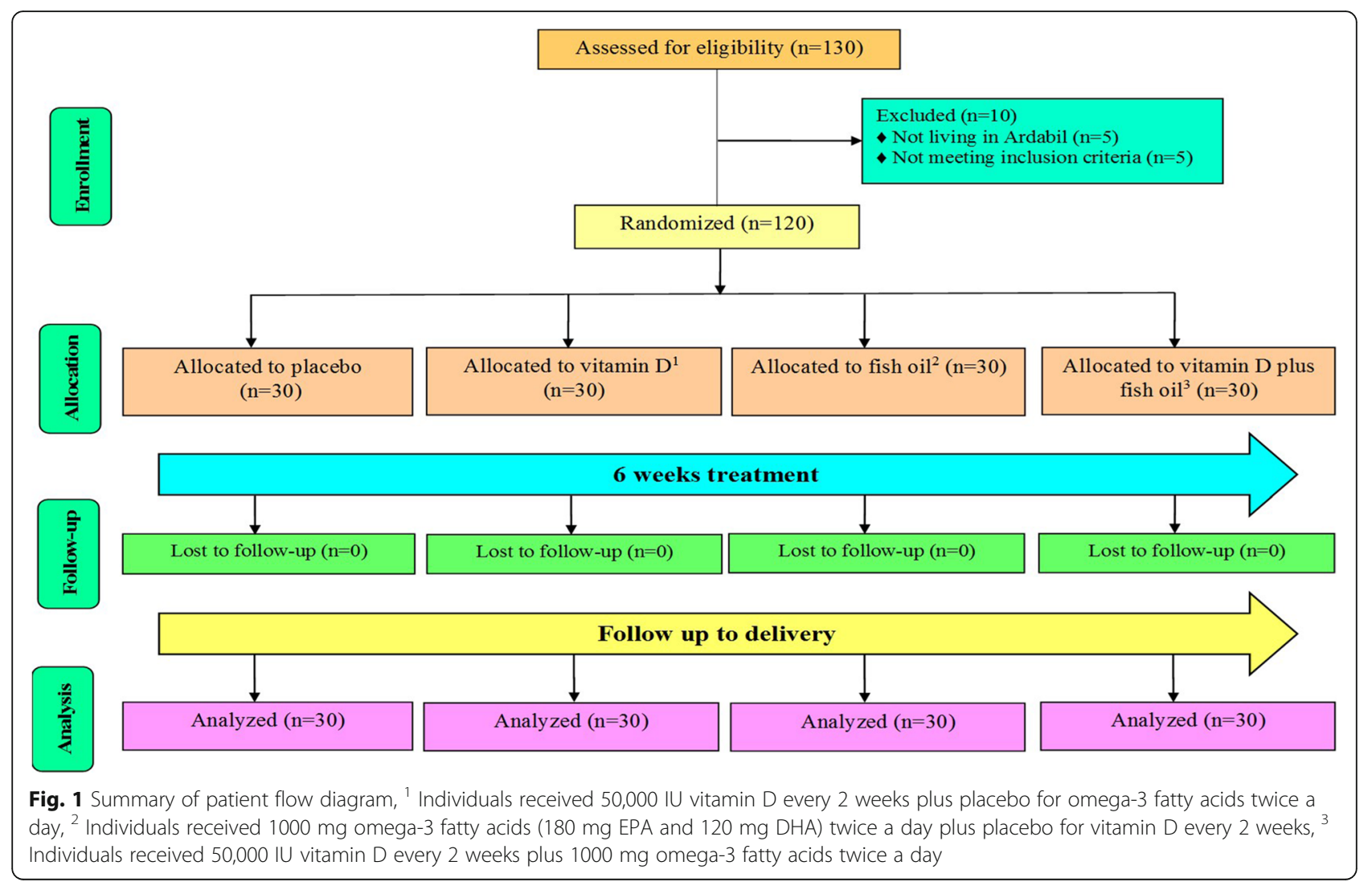

were reported following the supplementation of vitamin $\mathrm{D}$ and omega-3 fatty acids supplements in women with GDM throughout the study.

Mean age and height of study participants were not statistically different between the four groups (Table 1). Baseline weight and BMI as well as their means after intervention were not significant different comparing the groups.

Based on the 3-day dietary records obtained throughout the intervention, no statistically significant change was seen between the four groups in terms of dietary intakes of macro- and micronutrients (Data not shown).

After 6 weeks of intervention, co-supplementation with vitamin $\mathrm{D}$ and omega-3 fatty acids led to a significant increase in serum 25-hydroxyvitamin $D$ values $(+19.5 \pm 3.2$ vs. $+18.1 \pm 4.4,+0.7 \pm 2.8$ and $-0.2 \pm 1.7 \mathrm{ng} / \mathrm{mL}$, respectively, $P<0.001)$ compared with vitamin $\mathrm{D}$, omega-3 fatty acids and placebo (Table 2). In addition, subjects who received vitamin D plus omega-3 fatty acids supplements compared with vitamin D, omega-3 fatty acids and placebo

Table 1 General characteristics of study participants ${ }^{1}$

\begin{tabular}{|c|c|c|c|c|c|}
\hline & $\begin{array}{l}\text { Placebo } \\
(n=30)\end{array}$ & $\begin{array}{l}\text { Vitamin } \mathrm{D}^{2} \\
(n=30)\end{array}$ & $\begin{array}{l}\text { Omega- } 3^{3} \\
(n=30)\end{array}$ & $\begin{array}{l}\text { Vitamin D+ omega- } 3^{4} \\
(n=30)\end{array}$ & $\mathrm{P}^{5}$ \\
\hline Age (y) & $29.2 \pm 3.4$ & $29.9 \pm 5.0$ & $29.7 \pm 3.6$ & $29.9 \pm 4.0$ & 0.869 \\
\hline Height (cm) & $161.6 \pm 4.8$ & $161.5 \pm 4.1$ & $161.5 \pm 3.4$ & $161.8 \pm 3.7$ & 0.985 \\
\hline Weight at study baseline (kg) & $75.1 \pm 7.7$ & $76.1 \pm 12.7$ & $74.3 \pm 5.8$ & $77.4 \pm 10.2$ & 0.632 \\
\hline Weight at end-of-trial (kg) & $77.5 \pm 7.7$ & $78.6 \pm 12.5$ & $76.7 \pm 6.1$ & $80.0 \pm 10.0$ & 0.559 \\
\hline Weight change (kg) & $2.3 \pm 0.7$ & $2.5 \pm 1.1$ & $2.4 \pm 0.5$ & $2.6 \pm 0.6$ & 0.570 \\
\hline BMI at study baseline $\left(\mathrm{kg} / \mathrm{m}^{2}\right)$ & $28.8 \pm 3.4$ & $29.2 \pm 5.0$ & $28.5 \pm 2.4$ & $29.5 \pm 3.8$ & 0.746 \\
\hline BMI at end-of-trial $\left(\mathrm{kg} / \mathrm{m}^{2}\right)$ & $29.7 \pm 3.4$ & $30.1 \pm 4.8$ & $29.4 \pm 2.5$ & $30.5 \pm 3.7$ & 0.683 \\
\hline BMI change $\left(\mathrm{kg} / \mathrm{m}^{2}\right)$ & $0.9 \pm 0.3$ & $1.0 \pm 0.4$ & $0.9 \pm 0.2$ & $1.0 \pm 0.2$ & 0.592 \\
\hline
\end{tabular}

${ }^{1}$ Data are means \pm SDs

${ }^{2}$ Receiving 50,000 IU vitamin D every 2 weeks plus placebo for omega-3 fatty acids twice a day

${ }^{3}$ Receiving $1000 \mathrm{mg}$ omega-3 fatty acids (180 mg EPA and $120 \mathrm{mg} \mathrm{DHA}$ ) twice a day plus placebo for vitamin D every 2 weeks

${ }^{4}$ Receiving 50,000 IU vitamin D every 2 weeks plus $1000 \mathrm{mg}$ omega-3 fatty acids twice a day

${ }^{5}$ Obtained from ANOVA test 
Table 2 The effect of vitamin D plus omega-3 fatty acids supplementations on biomarkers of inflammation and oxidative in gestational diabetes patients ${ }^{1}$

\begin{tabular}{|c|c|c|c|c|c|}
\hline & $\begin{array}{l}\text { Placebo } \\
(n=30)\end{array}$ & $\begin{array}{l}\text { Vitamin } D^{2} \\
(n=30)\end{array}$ & $\begin{array}{l}\text { Omega- } 3^{3} \\
(n=30)\end{array}$ & $\begin{array}{l}\text { Vitamin D+ omega-3 }{ }^{4} \\
(n=30)\end{array}$ & $P^{5}$ \\
\hline \multicolumn{6}{|c|}{ Serum 25-OH-vitamin D (ng/mL) } \\
\hline Baseline & $14.9 \pm 3.2$ & $13.6 \pm 3.7$ & $15.6 \pm 4.0$ & $14.2 \pm 2.9$ & 0.156 \\
\hline End & $14.7 \pm 3.2$ & $31.7 \pm 6.8$ & $16.3 \pm 4.6$ & $33.8 \pm 4.6$ & $<0.001$ \\
\hline Change & $-0.2 \pm 1.7$ & $18.1 \pm 4.4^{b}$ & $0.7 \pm 2.8$ & $19.5 \pm 3.2^{b}$ & $<0.001$ \\
\hline \multicolumn{6}{|c|}{ hs-CRP (mg/L) } \\
\hline Baseline & $7.2 \pm 3.9$ & $7.2 \pm 6.4$ & $8.0 \pm 6.2$ & $8.3 \pm 4.6$ & 0.815 \\
\hline End & $8.1 \pm 4.0$ & $6.4 \pm 3.9$ & $6.7 \pm 5.9$ & $6.3 \pm 4.7$ & 0.407 \\
\hline Change & $0.9 \pm 2.7$ & $-0.8 \pm 4.4$ & $-1.3 \pm 2.4$ & $-2.0 \pm 3.3^{a}$ & 0.008 \\
\hline \multicolumn{6}{|c|}{$\mathrm{NO}(\mu \mathrm{mol} / \mathrm{L})$} \\
\hline Baseline & $51.1 \pm 13.0$ & $54.1 \pm 4.9$ & $46.9 \pm 4.9$ & $46.1 \pm 5.2$ & $<0.001$ \\
\hline End & $52.5 \pm 15.4$ & $60.0 \pm 7.9$ & $51.5 \pm 7.3$ & $48.4 \pm 5.1$ & $<0.001$ \\
\hline Change & $1.4 \pm 11.4$ & $5.9 \pm 9.0$ & $4.6 \pm 9.2$ & $2.3 \pm 7.5$ & 0.230 \\
\hline \multicolumn{6}{|c|}{ TAC (mmol/L) } \\
\hline Baseline & $748.1 \pm 109.7$ & $807.2 \pm 96.6$ & $811.0 \pm 54.3$ & $906.4 \pm 73.9$ & $<0.001$ \\
\hline End & $749.1 \pm 91.2$ & $862.3 \pm 91.9$ & $899.4 \pm 112.8$ & $998.5 \pm 82.1$ & $<0.001$ \\
\hline Change & $1.0 \pm 90.8$ & $55.1 \pm 123.6$ & $88.4 \pm 95.2^{\mathrm{a}}$ & $92.1 \pm 70.1^{a}$ & 0.001 \\
\hline \multicolumn{6}{|c|}{ GSH ( $\mu \mathrm{mol} / \mathrm{L})$} \\
\hline Baseline & $491.8 \pm 173.5$ & $456.6 \pm 67.8$ & $532.5 \pm 49.6$ & $518.3 \pm 64.2$ & 0.020 \\
\hline End & $484.0 \pm 161.2$ & $479.6 \pm 59.7$ & $562.5 \pm 57.8$ & $594.2 \pm 60.9$ & $<0.001$ \\
\hline Change & $-7.8 \pm 126.5$ & $23.0 \pm 62.3$ & $30.0 \pm 66.5$ & $75.9 \pm 86.7^{\mathrm{a}}$ & 0.005 \\
\hline \multicolumn{6}{|c|}{ MDA ( $\mu \mathrm{mol} / \mathrm{L})$} \\
\hline Baseline & $3.2 \pm 1.0$ & $2.7 \pm 0.4$ & $3.5 \pm 0.8$ & $3.0 \pm 0.5$ & $<0.001$ \\
\hline End & $3.7 \pm 1.6$ & $2.5 \pm 0.3$ & $3.2 \pm 0.4$ & $2.5 \pm 0.3$ & $<0.001$ \\
\hline Change & $0.5 \pm 1.4$ & $-0.2 \pm 0.5^{\mathrm{a}}$ & $-0.3 \pm 0.9^{\mathrm{a}}$ & $-0.5 \pm 0.5^{a}$ & $<0.001$ \\
\hline
\end{tabular}

${ }^{1}$ Data are means \pm SDs

${ }^{2}$ Receiving 50,000 IU vitamin D every 2 weeks plus placebo for omega-3 fatty acids twice a day

${ }^{3}$ Receiving $1000 \mathrm{mg}$ omega-3 fatty acids (180 mg EPA and $120 \mathrm{mg}$ DHA) twice a day plus placebo for vitamin D every 2 weeks

${ }^{4}$ Receiving 50,000 IU vitamin D every 2 weeks plus $1000 \mathrm{mg}$ omega-3 fatty acids twice a day

${ }^{5}$ Obtained from ANOVA test

GSH, glutathione; hs-CRP, high-sensitivity C-reactive protein; MDA, malondialdehyde; NO, nitric oxide; TAC, total antioxidant capacity

${ }^{a}$ Significant difference with the placebo group

${ }^{\mathrm{b}}$ Significant difference with the placebo and omega-3 fatty acids groups

had significantly decreased serum hs-CRP $(-2.0 \pm 3.3$ vs. $-0.8 \pm 4.4,-1.3 \pm 2.4$ and $+0.9 \pm 2.7 \mathrm{mg} / \mathrm{L}$, respectively, $P=$ $0.008)$, plasma MDA ( $-0.5 \pm 0.5$ vs. $-0.2 \pm 0.5,-0.3 \pm 0.9$ and $+0.5 \pm 1.4 \mu \mathrm{mol} / \mathrm{L}$, respectively, $P<0.001)$, and increased plasma TAC $(+92.1 \pm 70.1$ vs. $+55.1 \pm 123.6,+88.4 \pm 95.2$ and $+1.0 \pm 90.8 \mathrm{mmol} / \mathrm{L}$, respectively, $P=0.001)$ and GSH levels $(+95.7 \pm 86.7$ vs. $+23.0 \pm 62.3,+30.0 \pm 66.5$ and $-7.8 \pm$ $126.5 \mu \mathrm{mol} / \mathrm{L}$, respectively, $\mathrm{P}=0.001$ ). Co-supplementation with vitamin $\mathrm{D}$ and omega-3 fatty acids had no significant effect on plasma NO levels.

There was a significant difference in baseline levels of plasma NO $(P<0.001)$, TAC $(P<0.001)$, GSH $(P=$ $0.02)$ and MDA $(P<0.001)$ between the four groups. When we adjusted the analysis for baseline values of biochemical parameters, age and baseline BMI, findings did not change except plasma NO levels (0.020) (Table 3).

Vitamin D and omega-3 fatty acids co-supplementation, compared with vitamin $\mathrm{D}$, omega-3 fatty acids and placebo, resulted in lower incidences of newborns' hyperbilirubinemiain $(10.0 \%$ vs. $20.0 \%, 33.3 \%$ and $40.0 \%$, respectively, $P=0.037)$ and newborns' hospitalization $(10.0 \%$ vs. $20.0 \%, 33.3 \%$ and $40.0 \%$, respectively, $P=0.037)$, but did not affect other pregnancy outcomes (Table 4).

\section{Discussion}

To our knowledge, this study is the first report of the effects of vitamin D and omega-3 fatty acids co-supplementation on biomarkers of inflammation, oxidative stress and pregnancy outcomes among women with GDM. We found that 
Table 3 Adjusted changes in metabolic variables in gestational diabetes patients that received either vitamin D plus omega-3 fatty acids, omega-3 fatty acids and vitamin D supplements or placebo ${ }^{1}$

\begin{tabular}{|c|c|c|c|c|c|}
\hline & $\begin{array}{l}\text { Placebo } \\
(n=30)\end{array}$ & $\begin{array}{l}\text { Vitamin } \mathrm{D}^{2} \\
(n=30)\end{array}$ & $\begin{array}{l}\text { Omega- } 3^{3} \\
(n=30)\end{array}$ & $\begin{array}{l}\text { Vitamin D+ omega- } 3^{4} \\
(n=30)\end{array}$ & $P^{5}$ \\
\hline Serum 25-OH-vitamin D (ng/mL) & $-0.2 \pm 0.6$ & $18.2 \pm 0.6$ & $0.7 \pm 0.6$ & $19.5 \pm 0.6$ & $<0.001$ \\
\hline hs-CRP (mg/L) & $0.8 \pm 0.5$ & $-1.0 \pm 0.5$ & $-1.2 \pm 0.5$ & $-1.9 \pm 0.5$ & 0.004 \\
\hline $\mathrm{NO}(\mu \mathrm{mol} / \mathrm{L})$ & $1.9 \pm 1.6$ & $7.9 \pm 1.6$ & $3.3 \pm 1.6$ & $1.0 \pm 1.6$ & 0.020 \\
\hline TAC (mmol/L) & $-35.5 \pm 17.1$ & $49.1 \pm 15.9$ & $85.5 \pm 15.8$ & $137.6 \pm 17.8$ & $<0.001$ \\
\hline GSH $(\mu \mathrm{mol} / \mathrm{L})$ & $-12.4 \pm 14.2$ & $5.6 \pm 14.5$ & $45.2 \pm 14.4$ & $83.8 \pm 14.3$ & $<0.001$ \\
\hline MDA ( $\mu \mathrm{mol} / \mathrm{L})$ & $0.5 \pm 0.1$ & $-0.4 \pm 0.2$ & $-0.1 \pm 0.2$ & $-0.5 \pm 0.1$ & $<0.001$ \\
\hline
\end{tabular}

${ }^{1}$ All values are means \pm SEs. Values are adjusted for baseline values of parameters of biochemical, age and baseline BMI

${ }^{2}$ Receiving 50,000 IU vitamin D every 2 weeks plus placebo for omega-3 fatty acids twice a day

${ }^{3}$ Receiving $1000 \mathrm{mg}$ omega-3 fatty acids (180 mg EPA and $120 \mathrm{mg}$ DHA) twice a day plus placebo for vitamin D every 2 weeks

${ }^{4}$ Receiving 50,000 IU vitamin D every 2 weeks plus $1000 \mathrm{mg}$ omega-3 fatty acids twice a day

${ }^{5}$ Obtained from ANCOVA test

GSH, glutathione; hs-CRP, high-sensitivity C-reactive protein; MDA, malondialdehyde; NO, nitric oxide; TAC, total antioxidant capacity

vitamin D and omega-3 fatty acids co-supplementation for 6 weeks to GDM women had beneficial effects on maternal serum hs-CRP, plasma TAC, GSH, MDA levels, and newborns' hyperbilirubinemiain and hospitalization, but did not influence plasma NO levels and other pregnancy outcomes. In the current study, we hypothesized that combined therapy with vitamin D and omega-3 fatty acids in GDM women may work better than a single supplementation alone. In addition, vitamin D and omega-3 fatty acids co-supplementation might have a strong synergistic effect on biomarkers of inflammation, oxidative stress and pregnancy outcomes. In a study by Baidal et al. [28], it was observed that combined omega-3 fatty acids and vitamin D3 therapy was well tolerated and had beneficial effects on beta-cell function in patients with onset type 1 diabetes. Gurol et al. [29] also demonstrated that omega-3 fatty acids and vitamin D had a synergistic effect on glycemia in islet transplantation. Furthermore, omega- 3 fatty acids supplementation may result in increased circulating levels of vitamin D. In a study by An et al. [30], it was seen that $1,25(\mathrm{OH})_{2} \mathrm{D}$ levels significantly increased in dialysis patients compared to baseline after 3 months of omega-3 fatty acids supplementation without vitamin D. Omega-3 fatty acids intake may also overcome the inverse association of vitamin $\mathrm{D}$ deficiency with

Table 4 The association of vitamin D plus omega-3 fatty acids supplementation with pregnancy outcomes

\begin{tabular}{|c|c|c|c|c|c|}
\hline & $\begin{array}{l}\text { Placebo group } \\
(n=30)\end{array}$ & $\begin{array}{l}\text { Vitamin } \mathrm{D}^{2} \\
(n=30)\end{array}$ & $\begin{array}{l}\text { Omega- } 3^{3} \\
(n=30)\end{array}$ & $\begin{array}{l}\text { Vitamin D+ omega-3 }{ }^{4} \\
(n=30)\end{array}$ & $\mathrm{P}^{5}$ \\
\hline Cesarean section (\%) & $11(36.7)$ & $9(30.0)$ & $9(30.0)$ & $8(26.7)$ & $0.863^{\dagger}$ \\
\hline Preterm delivery (\%) & $1(3.3)$ & $0(0.0)$ & $0(0.0)$ & $0(0.0)$ & $0.388^{\dagger}$ \\
\hline Pre-eclampsia (\%) & $3(10.0)$ & $3(10.0)$ & $2(6.7)$ & $3(10.0)$ & $0.960^{\dagger}$ \\
\hline Polyhydramnios (\%) & $2(6.6)$ & $2(6.6)$ & $2(6.6)$ & $2(6.6)$ & $>0.999^{\dagger}$ \\
\hline Macrosomia > $4000 \mathrm{~g}(\%)$ & $5(16.7)$ & $2(6.7)$ & $3(10.0)$ & $2(6.7)$ & $0.525^{\dagger}$ \\
\hline Gestational age (weeks) & $39.1 \pm 1.1$ & $39.2 \pm 1.0$ & $39.0 \pm 1.4$ & $39.3 \pm 0.9$ & 0.658 \\
\hline Newborns' weight (g) & $3323.0 \pm 407.1$ & $3308.3 \pm 604.0$ & $3475.0 \pm 395.2$ & $3311.7 \pm 502.2$ & 0.480 \\
\hline Newborns' length (cm) & $50.4 \pm 1.1$ & $50.2 \pm 3.0$ & $51.3 \pm 2.1$ & $49.9 \pm 2.7$ & 0.103 \\
\hline Newborns' head circumference $(\mathrm{cm})$ & $35.7 \pm 1.3$ & $35.9 \pm 2.9$ & $35.5 \pm 1.4$ & $35.3 \pm 2.7$ & 0.744 \\
\hline 1- min Apgar score & $8.8 \pm 0.4$ & $8.7 \pm 0.4$ & $8.7 \pm 0.4$ & $8.8 \pm 0.4$ & 0.779 \\
\hline 5- min Apgar score & $9.8 \pm 0.4$ & $9.7 \pm 0.4$ & $9.7 \pm 0.4$ & $9.8 \pm 0.4$ & 0.779 \\
\hline Newborns' hyperbilirubinemia (\%) & $12(40.0)$ & $6(20.0)$ & $10(33.3)$ & $3(10.0)$ & $0.037^{\dagger}$ \\
\hline Newborns' hospitalization (\%) & $12(40.0)$ & $6(20.0)$ & $10(33.3)$ & $3(10.0)$ & $0.037^{\dagger}$ \\
\hline Newborns' hypoglycemia (\%) & $6(20.0)$ & $4(13.3)$ & $5(16.7)$ & $4(13.3)$ & $0.876^{\dagger}$ \\
\hline
\end{tabular}

Values are means \pm SDs for continuous measures and are number (\%) for dichotomous variables

${ }^{\dagger}$ Obtained from Pearson Chi-square test

${ }^{2}$ Receiving 50,000 IU vitamin D every 2 weeks plus placebo for omega-3 fatty acids twice a day

${ }^{3}$ Receiving $1000 \mathrm{mg}$ omega-3 fatty acids (180 mg EPA and $120 \mathrm{mg}$ DHA) twice a day plus placebo for vitamin D every 2 weeks

${ }^{4}$ Receiving 50,000 IU vitamin D every 2 weeks plus $1000 \mathrm{mg}$ omega-3 fatty acids twice a day

${ }^{5}$ Obtained from ANOVA test 
inflammation [31]. As most patients of our study had vitamin $\mathrm{D}$ deficiency, decreased inflammatory markers may improve pregnancy outcomes.

The current study showed that vitamin D and omega3 fatty acids co-supplementation to GDM women for 6 weeks resulted in a significant reduction in serum hsCRP, but did not affect plasma NO levels compared with other groups. Although few studies have assessed beneficial effects of vitamin D or omega-3 fatty acids supplementation on inflammatory cytokines, to the best of our knowledge, data on the effects of vitamin D and omega3 fatty acids co-supplementation on inflammatory cytokines are scarce. We have previously demonstrated that supplementation with 50,000 IU of vitamin D every 3 weeks [11] or $1000 \mathrm{mg} /$ day of omega-3 fatty acids [12] for 6 weeks to GDM women had beneficial effects on few pregnancy outcomes. Likewise, in some studies, vitamin $\mathrm{D}$ supplementation in patients with a history of myocardial infarction and elderly women with vitamin D deficiency was associated with a significant reduction in circulating levels of CRP [32, 33]. The administration of fish oil at a dosage of $3 \mathrm{~g} /$ day to men with coronary artery disease for 8 weeks decreased hs-CRP levels [34]. However, in GDM women, vitamin D supplementation at a dosage of 50,000 IU every 2 weeks for 2 months had no significant effect on hs-CRP levels [20]. In addition, short-term omega-3 fatty acids supplementation (3 g/day for 8 weeks) in patients with T2DM could not affect CRP levels [35]. Increasing production of inflammatory cytokines in GDM would result in increased adiposity at birth [36] as well as predisposes the newborn to become overweight and develop metabolic diseases including glucose intolerance, metabolic syndrome, and cardiovascular disease [37, 38]. Less production of parathyroid hormone after vitamin D intake [39] might result in the reducing production of inflammatory factors including CRP. Furthermore, increased gene expression of peroxisome proliferator-activated receptors by omega-3 inhibits the activation of NF- $\mathrm{kB}$ [18], which in turn can decrease the production of inflammatory cytokines.

We demonstrated that vitamin D plus omega-3 fatty acids supplementation in GDM women for 6 weeks led to significant increases in plasma TAC and GSH concentrations, and a significant decrease in plasma MDA levels compared with other groups. Similarly our findings were observed following high-dose vitamin D supplementation (50,000 IU every 2 weeks) increased TAC and GSH concentrations in patients with GDM [40]. In addition, supplementation with vitamin D at a dosage of 200,000 IU significantly increased TAC levels in elderly subjects with vitamin D insufficiency [33]. Vitamin D supplementation at a dosage of 100,000 IU monthly for 3 months to overweight and obese subjects also decreased oxidative stress mediators of arterial stiffness [41]. On the other hand, a significant beneficial effect was seen following supplementation with $400 \mathrm{mg} /$ day of DHA for 2 weeks on platelet function and oxidative stress in patients with T2DM [42]. Furthermore, fish oil supplementation significantly decreased biomarkers of oxidative stress after a single bout of eccentric exercise in healthy man [43]. However, supplementation of fish oil to patients with Alzheimer's disease for 6 months did not affect biomarkers of oxidative stress [44]. Oxidative stress imbalance in GDM is important in the pathophysiological processes involved in vascular diseases, such as diabetes, hypertension and cardiovascular diseases [45]. Vitamin D intake can improve oxidative stress through its antioxidant properties [46], and decreasing production of reactive oxygen species and pro-inflammatory cytokines [47]. In addition, observed beneficial effects on biomarkers of oxidative stress by omega- 3 fatty acids may be mediated by their antiinflammatory properties [48].

It must be kept in mind that in the current study, vitamin D and omga-3 fatty acids co-supplementation may have an indirect role in newborns' hyperbilirubinemia and hospitalization due to their effects on improved biomarkers of inflammation and oxidative stress. In a study by Kalra et al. [49], it observed that supplementation with one dose of $1500 \mu \mathrm{g}$ vitamin D3 in the second trimester or two doses of $3000 \mu \mathrm{g}$ vitamin D3 each in the second and third trimesters resulted in improved liver enzyme levels in cord blood of the infants. In addition, fish oil supplementation $(0.2 \mathrm{~g} / \mathrm{kg}$ body weight daily) for 5 days in postoperative cancer subjects was associated with significant reductions of bilirubin and liver enzymes levels [50]. However, supplementation with $25 \mathrm{mg} /$ day of ergocalciferol to pregnant women did not affect mean birth weight [51, 52]. Moreover, supplementation with $600 \mathrm{mg} /$ day of DHA in the last half of gestation resulted in overall greater gestation duration and infant size [53]. Active form of vitamin $\mathrm{D}$ induces vitamin $\mathrm{D}$ receptors, which in turn act as a receptor for secondary bile acids, such as lithocholic acid and 3-ketocholanic acid, and leads to their catabolism via induction of cytochrome $3 \mathrm{~A}$ enzymes $[17,54]$.

Few limitations must be considered in the interpretation of our findings. The main limitation of our study is the lack of measurements of circulating levels of EPA, DHA and other omega- 3 fatty acids at baseline and after the 6week intervention due to budget limitations. In addition, further studies are needed to assess the gene expression related to inflammation and oxidative stress to explore the plausible mechanism and confirm our findings.

\section{Conclusions}

Overall, vitamin $\mathrm{D}$ and omega-3 fatty acids cosupplementation for 6 weeks among GDM women had beneficial effects on some biomarkers of inflammation, oxidative stress and pregnancy outcomes. 


\section{Abbreviations}

AFI: Amniotic fluid index; BMl: Body mass index; CAD: Coronary artery disease; DHA: Docosahexaenoic acid; ELISA: Enzyme-linked immunosorbent assay; EPA: Eicosapentaenoic acid; GDM: Gestational diabetes mellitus; GSH: Glutathione; hs-CRP: High-sensitivity C-reactive protein; MDA: Malondialdehyde; METs: Metabolic equivalents; NF-kB: Nuclear factorKB; NO: Nitric oxide; T2DM: Type 2 diabetes mellitus; TAC: Total Antioxidant Capacity

\section{Acknowledgements}

The present study was supported by a grant from the Vice-chancellor for Research, AUMS, Iran.

\section{Funding}

The research grant provided by Research Deputy of Ardabil University of Medical Sciences (AUMS).

\section{Availability of data and materials}

The primary data for this study is available from the authors on direct request.

\section{Authors' contributions}

ZA contributed in conception, data collection and manuscript drafting. MR $M J, M S, F A-E, M T, R B, E S-H, H H-K$ and MK contributed in conception, data collection and manuscript drafting. All authors read and approved the final version of the paper.

\section{Ethics approval and consent to participate}

All procedures performed in studies involving human participants were in accordance with the ethical standards of the institutional and national research committee and with the 1964 Helsinki declaration and its later amendments.

\section{Consent for publication}

Not applicable.

\section{Competing interests}

The authors declare no competing interest.

\section{Publisher's Note}

Springer Nature remains neutral with regard to jurisdictional claims in published maps and institutional affiliations.

\section{Author details}

'Department of Gynecology and Obstetrics, School of Medicine, Ardabil University of Medical Sciences, Ardabil, Iran. ${ }^{2}$ Endocrinology and Metabolism Research Center, Department of Gynecology and Obstetrics, School of Medicine, Arak University of Medical Sciences, Arak, Iran. ${ }^{3}$ Department of Gynecology and Obstetrics, School of Medicine, Kashan University of Medical Sciences, Kashan, Iran. ${ }^{4}$ Research Center for Biochemistry and Nutrition in Metabolic Diseases, Kashan University of Medical Sciences, PO Box 8715988141, Kashan, Iran. ${ }^{5}$ Barij Medicinal Plants Research Center, Kashan, Iran. ${ }^{6}$ Anatomical Sciences Research Center, Kashan University of Medical Sciences, Kashan, Iran. ${ }^{7}$ Department of Gynecology and Obstetrics, School of Medicine, Iran University of Medical Sciences, Tehran, Iran.

Received: 31 August 2017 Accepted: 15 December 2017

Published online: 28 December 2017

\section{References}

1. Abariga SA, Whitcomb BW. Periodontitis and gestational diabetes mellitus: a systematic review and meta-analysis of observational studies. BMC Pregnancy Childbirth. 2016;16:344

2. Hanna FW, Duff CJ, Shelley-Hitchen A, Hodgson E, Fryer AA. Diagnosing gestational diabetes mellitus: implications of recent changes in diagnostic criteria and role of glycated haemoglobin (HbA1c). Clin Med (Lond). 2017; 17:108-13.

3. Lavery JA, Friedman AM, Keyes KM, Wright JD, Ananth CV. Gestational diabetes in the United States: temporal changes in prevalence rates between 1979 and 2010. BJOG. 2017;124:804-13.
4. Hossein-Nezhad A, Maghbooli Z, Vassigh AR, Larijani B. Prevalence of gestational diabetes mellitus and pregnancy outcomes in Iranian women. Taiwan J Obstet Gynecol. 2007;46:236-41.

5. Blickstein I, Doyev R, Trojner Bregar A, Brzan Simenc G, Verdenik I, Tul N. The effect of gestational diabetes, pre-gravid maternal obesity, and their combination ('diabesity') on outcomes of singleton gestations. J Matern Fetal Neonatal Med. 2017:1-4.

6. Bellamy L, Casas JP, Hingorani AD, Williams D. Type 2 diabetes mellitus after gestational diabetes: a systematic review and meta-analysis. Lancet. 2009; 373:1773-9.

7. Teler J, Tarnowski M, Safranow K, Maciejewska A, Sawczuk M, Dziedziejko V, Sluczanowska-Glabowska S, Pawlik A. CCL2, CCL5, IL4 and IL15 Gene Polymorphisms in Women with Gestational Diabetes Mellitus. Horm Metab Res. 2017:49:10-5

8. Toljic M, Egic A, Munjas J, Karadzov Orlic N, Milovanovic Z, Radenkovic A, Vuceljic J, Joksic I. Increased oxidative stress and cytokinesis-block micronucleus cytome assay parameters in pregnant women with gestational diabetes mellitus and gestational arterial hypertension. Reprod Toxicol. 2017:71:55-62.

9. Haidari F, Jalali MT, Shahbazian N, Haghighizadeh MH, Azadegan E. Comparison of serum levels of vitamin $\mathrm{D}$ and inflammatory markers between women with gestational diabetes mellitus and healthy pregnant control. J Family Reprod Health. 2016;10:1-8.

10. Bitsanis D, Ghebremeskel K, Moodley T, Crawford MA, Djahanbakhch O. Gestational diabetes mellitus enhances arachidonic and docosahexaenoic acids in placental phospholipids. Lipids. 2006;41:341-6.

11. Asemi Z, Karamali M, Esmaillzadeh A. Favorable effects of vitamin D supplementation on pregnancy outcomes in gestational diabetes: a double blind randomized controlled clinical trial. Horm Metab Res. 2015;47:565-70.

12. Jamilian M, Samimi M, Kolahdooz F, Khalaji F, Razavi M, Asemi Z. Omega-3 fatty acid supplementation affects pregnancy outcomes in gestational diabetes: a randomized, double-blind, placebo-controlled trial. J Matern Fetal Neonatal Med. 2016;29:669-75.

13. Mojibian M, Soheilykhah S, Fallah Zadeh MA, Jannati Moghadam M. The effects of vitamin D supplementation on maternal and neonatal outcome: a randomized clinical trial. Iran J Reprod Med. 2015;13:687-96.

14. Chen B, Ji X, Zhang L, Hou Z, Li C, Tong Y. Fish oil supplementation improves pregnancy outcomes and size of the newborn: a meta-analysis of 21 randomized controlled trials. J Matern Fetal Neonatal Med. 2016;29:2017-27.

15. Zhou SJ, Yelland L, McPhee AJ, Quinlivan J, Gibson RA, Makrides M. Fish-oil supplementation in pregnancy does not reduce the risk of gestational diabetes or preeclampsia. Am J Clin Nutr. 2012;95:1378-84.

16. Nobile de Santis MS, Radaelli T, Taricco E, Bertini S, Cetin I. Excess of amniotic fluid: pathophysiology, correlated diseases and clinical management. Acta Biomed. 2004;75(Suppl 1):53-5.

17. Makishima M, TT L, Xie W, Whitfield GK, Domoto H, Evans RM, Haussler MR, Mangelsdorf DJ, Vitamin D. Receptor as an intestinal bile acid sensor. Science. 2002;296:1313-6.

18. Rossi A, Kapahi P, Natoli G, Takahashi T, Chen Y, Karin M, Santoro MG. Antiinflammatory cyclopentenone prostaglandins are direct inhibitors of IkappaB kinase. Nature. 2000:403:103-8.

19. American Diabetes Association. Diagnosis and classification of diabetes mellitus. Diabetes Care. 2014;37 Suppl 1:S81-90.

20. Yazdchi R, Gargari BP, Asghari-Jafarabadi M, Sahhaf F. Effects of vitamin D supplementation on metabolic indices and hs-CRP levels in gestational diabetes mellitus patients: a randomized, double-blinded, placebo-controlled clinical trial. Nutr Res Pract. 2016;10:328-35.

21. Bowden RG, Wilson RL, Deike $E$, Gentile M. Fish oil supplementation lowers C-reactive protein levels independent of triglyceride reduction in patients with end-stage renal disease. Nutr Clin Pract. 2009;24:508-12.

22. Ainsworth BE, Haskell WL, Whitt MC, Irwin ML, Swartz AM, Strath SJ, et al. Compendium of physical activities: an update of activity codes and MET intensities. Med Sci Sports Exerc. 2000;32:S498-504.

23. Tatsch E, Bochi GV, Pereira Rda S, Kober H, Agertt VA, de Campos MM, Gomes P, Duarte MM, Moresco RNA. Simple and inexpensive automated technique for measurement of serum nitrite/nitrate. Clin Biochem. 2011;44:348-50

24. Benzie IF, Strain JJ. The ferric reducing ability of plasma (FRAP) as a measure of "antioxidant power": the FRAP assay. Anal Biochem. 1996;239:70-6.

25. Beutler E, Gelbart T. Plasma glutathione in health and in patients with malignant disease. J Lab Clin Med. 1985;105:581-4. 
26. Janero DR. Malondialdehyde and thiobarbituric acid-reactivity as diagnostic indices of lipid peroxidation and peroxidative tissue injury. Free Radic Biol Med. 1990;9:515-40.

27. Porter ML, Dennis BL. Hyperbilirubinemia in the term newborn. Am Fam Physician. 2002;65:599-606.

28. Baidal DA, Ricordi C, Garcia-Contreras M, Sonnino A, Fabbri A. Combination high-dose omega-3 fatty acids and high-dose cholecalciferol in new onset type 1 diabetes: a potential role in preservation of beta-cell mass. Eur Rev Med Pharmacol Sci. 2016;20:3313-8.

29. Gurol AO, Okten-Kursun A, Kasapoglu P, Suzergoz F, Kucuksezer UC, Cevik A, Tutuncu Y, Yentur SP, Gurol SD, Kucuk M, Yilmaz MT. The synergistic effect of omega3 and Vit D3 on glycemia and TNF-alpha in islet transplantation. Cell Mol Biol (Noisy-le-grand). 2016;62:90-8.

30. An WS, Lee SM, Son YK, Kim SE, Kim KH, Han JY, Bae HR, Rha SH, Park Y. Omega-3 fatty acid supplementation increases 1,25-dihydroxyvitamin D and fetuin-a levels in dialysis patients. Nutr Res. 2012;32:495-502.

31. Itariu BK, Zeyda M, Leitner L, Marculescu R, Stulnig TM. Treatment with n-3 polyunsaturated fatty acids overcomes the inverse association of vitamin $D$ deficiency with inflammation in severely obese patients: a randomized controlled trial. PLoS One. 2013:8:e54634.

32. Witham MD, Dove FJ, Khan F, Lang CC, Belch JJ, Struthers AD. Effects of vitamin D supplementation on markers of vascular function after myocardial infarction-a randomised controlled trial. Int J Cardiol. 2013;167:745-9.

33. de Medeiros Cavalcante IG, Silva AS, Costa MJ, Persuhn DC, Issa CT, de Luna Freire TL, Conceicao Rodrigues d, Goncalves M. Effect of vitamin D3 supplementation and influence of Bsml polymorphism of the VDR gene of the inflammatory profile and oxidative stress in elderly women with vitamin D insufficiency: vitamin D3 megadose reduces inflammatory markers. Exp Gerontol. 2015;66:10-6.

34. Agh F, Mohammadzadeh Honarvar N, Djalali M, Nematipour E, Gholamhoseini S, Zarei M, Ansari S, Javanbakht MH. Omega-3 fatty acid could increase one of myokines in male patients with coronary artery disease: a randomized, double-blind, placebo-controlled trial. Arch Iran Med. 2017;20:28-33.

35. Malekshahi Moghadam A, Saedisomeolia A, Djalali M, Djazayery A, Pooya S, Sojoudi F. Efficacy of omega-3 fatty acid supplementation on serum levels of tumour necrosis factor-alpha, C-reactive protein and interleukin-2 in type 2 diabetes mellitus patients. Singap Med J. 2012;53:615-9.

36. Aramesh MR, Dehdashtian M, Malekian A, ShahAli S, Shojaei K. Relation between fetal anthropometric parameters and cord blood adiponectin and high-sensitivity C-reactive protein in gestational diabetes mellitus. Arch Endocrinol Metab. 2017;13:0. https://doi.org/10.1590/2359-3997000000235.

37. Marseille-Tremblay C, Ethier-Chiasson M, Forest JC, Giguere Y, Masse A, Mounier C, Lafond J. Impact of maternal circulating cholesterol and gestational diabetes mellitus on lipid metabolism in human term placenta. Mol Reprod Dev. 2008;75:1054-62.

38. Reece EA. The fetal and maternal consequences of gestational diabetes mellitus. J Matern Fetal Neonatal Med. 2010;23:199-203.

39. Struglia M, Stamerra CA, Di Giosia P, Giorgini P, Capanna C, Grassi D, Properzi G, Ferri C. Vitamin D deficiency and endothelial dysfunction in rheumatoid arthritis patients. J Hypertens. 2015;33 Suppl 1:e84.

40. Zhang Q, Cheng Y, He M, Li T, Ma Z, Cheng H. Effect of various doses of vitamin $\mathrm{D}$ supplementation on pregnant women with gestational diabetes mellitus: a randomized controlled trial. Exp Ther Med. 2016;12:1889-95.

41. Martins D, Meng YX, Tareen N, Artaza J, Lee JE, Farodolu C, Gibbons G, Norris $K$. The effect of short term vitamin D supplementation on the inflammatory and oxidative mediators of arterial stiffness. Health (Irvine Calif). 2014;6:1503-11.

42. Vericel E, Colas R, Calzada C, Le QH, Feugier N, Cugnet C, Vidal H, Laville M, Moulin P, Lagarde M. Moderate oral supplementation with docosahexaenoic acid improves platelet function and oxidative stress in type 2 diabetic patients. Thromb Haemost. 2015;114:289-96.

43. Gray P, Chappell A, Jenkinson AM, Thies F, Gray SR. Fish oil supplementation reduces markers of oxidative stress but not muscle soreness after eccentric exercise. Int J Sport Nutr Exerc Metab. 2014;24:206-14.

44. Freund-Levi Y, Vedin I, Hjorth E, Basun H, Faxen Irving G, Schultzberg M, Eriksdotter M, Palmblad J, Vessby B, Wahlund LO, Cederholm T, Basu S. Effects of supplementation with omega-3 fatty acids on oxidative stress and inflammation in patients with Alzheimer's disease: the OmegAD study. J Alzheimers Dis. 2014:42:823-31.
45. Vural M, Camuzcuoglu H, Toy H, Cece H, Aydin H, Eren MA, et al. Evaluation of the future atherosclerotic heart disease with oxidative stress and carotid artery intima media thickness in gestational diabetes mellitus. Endocr Res. 2012:37:145-53.

46. Cetinkalp S, Delen Y, Karadeniz M, Yuce G, Yilmaz C. The effect of 1alpha,25(OH)2D3 vitamin over oxidative stress and biochemical parameters in rats where type 1 diabetes is formed by streptozotocin. J Diabetes Complicat. 2009;23:401-8.

47. Jain SK, Micinski D, Vitamin D. Upregulates glutamate cysteine ligase and glutathione reductase, and GSH formation, and decreases ROS and MCP-1 and IL-8 secretion in high-glucose exposed U937 monocytes. Biochem Biophys Res Commun. 2013;437:7-11

48. Hassan Eftekhari M, Aliasghari F, Babaei-Beigi MA, Hasanzadeh J. Effect of conjugated linoleic acid and omega-3 fatty acid supplementation on inflammatory and oxidative stress markers in atherosclerotic patients. ARYA Atheroscler. 2013;9:311-8.

49. Kalra P, Das V, Agarwal A, Kumar M, Ramesh V, Bhatia E, Gupta S, Singh S, Saxena P, Bhatia V. Effect of vitamin D supplementation during pregnancy on neonatal mineral homeostasis and anthropometry of the newborn and infant. Br J Nutr. 2012;108:1052-8.

50. Heller AR, Rossel T, Gottschlich B, Tiebel O, Menschikowski M, Litz RJ, Zimmermann T, Koch T. Omega-3 fatty acids improve liver and pancreas function in postoperative cancer patients. Int J Cancer. 2004;111:611-6.

51. Delvin EE, Salle BL, Glorieux FH, Adeleine P, David LS, Vitamin D. Supplementation during pregnancy: effect on neonatal calcium homeostasis. J Pediatr. 1986;109:328-34.

52. Mallet E, Gugi B, Brunelle P, Henocq A, Basuyau JP, Lemeur H, Vitamin D. Supplementation in pregnancy: a controlled trial of two methods. Obstet Gynecol. 1986;68:300-4.

53. Carlson SE, Colombo J, Gajewski BJ, Gustafson KM, Mundy D, Yeast J, Georgieff MK, Markley LA, Kerling EH, Shaddy DJDHA. Supplementation and pregnancy outcomes. Am J Clin Nutr. 2013;97:808-15.

54. Xie W, Radominska-Pandya A, Shi Y, Simon CM, Nelson MC, Ong ES, Waxman DJ, Evans RM. An essential role for nuclear receptors SXR/PXR in detoxification of cholestatic bile acids. Proc Natl Acad Sci U S A. 2001;98: 3375-80.

\section{Submit your next manuscript to BioMed Central and we will help you at every step:}

- We accept pre-submission inquiries

- Our selector tool helps you to find the most relevant journal

- We provide round the clock customer support

- Convenient online submission

- Thorough peer review

- Inclusion in PubMed and all major indexing services

- Maximum visibility for your research

Submit your manuscript at www.biomedcentral.com/submit
C) Biomed Central 